\title{
Research on a Comprehensive Maintenance Optimization Strategy for an Offshore Wind Farm
}

\author{
Yang $\mathrm{Lu}^{*} \mathbb{C}$, Liping Sun and Yanzhuo Xue \\ College of Shipbuilding Engineering, Harbin Engineering University, Harbin 150001, China; \\ sunliping@hrbeu.edu.cn (L.S.); xueyanzhuo@hrbeu.edu.cn (Y.X.) \\ * Correspondence: luyang@hrbeu.edu.cn
}

Citation: Lu, Y.; Sun, L.; Xue, Y.

Research on a Comprehensive

Maintenance Optimization Strategy for an Offshore Wind Farm. Energies 2021, 14, 965. https://doi.org/ 10.3390/en14040965

Academic Editor: Finn

Gunnar Nielsen

Received: 5 January 2021

Accepted: 8 February 2021

Published: 11 February 2021

Publisher's Note: MDPI stays neutral with regard to jurisdictional claims in published maps and institutional affiliations.

Copyright: (c) 2021 by the authors. Licensee MDPI, Basel, Switzerland. This article is an open access article distributed under the terms and conditions of the Creative Commons Attribution (CC BY) license (https:// creativecommons.org/licenses/by/ $4.0 /)$.

\begin{abstract}
Offshore wind is considered a crucial part in the future energy supply. However, influenced by weather conditions, the maintenance of offshore wind turbine system (OWTs) equipment is challenged by poor accessibility and serious failure consequences. It is necessary to study the optimized strategy of comprehensive maintenance for offshore wind farms, with consideration of the influences of incomplete equipment maintenance, weather accessibility and economic relevance. In this paper, a Monte Carlo algorithm-improved factor is presented to simulate the imperfect preventive maintenance activity, and waiting windows were created to study the accessibility of weather conditions. Based on a rolling horizon approach, an opportunity group maintenance model of an offshore wind farm was proposed. The maintenance correlations between systems and between equipment as well as breakdown losses, maintenance uncertainty, and weather conditions were taken into account in the model, thus realizing coordination of maintenance activities of different systems and different equipment. The proposed model was applied to calculate the maintenance cost of the Dafengtian Offshore Wind Farm in China. Results proved that the proposed model could realize long-term dynamic optimization of offshore wind farm maintenance activities, increase the total availability of the wind power system and reduce total maintenance costs.
\end{abstract}

Keywords: offshore wind farm; weather availability; imperfect maintenance; opportunistic maintenance; rolling horizon approach

\section{Introduction}

Marine engineering equipment is usually located far away from the coastline. The complicated and varied marine environment not only increases the failure rate of components, but also brings great inconvenience to maintenance work. The construction, operation and maintenance of offshore wind farms are affected by the weather accessibility due to the special weather environment [1]. Different weather and sea conditions are important factors restricting maintenance activities. In general, offshore operations are difficult, expensive and time-consuming. Favorable operation conditions are the basis to ensure the accessibility of offshore engineering site and offshore operation. Professional marine transportation resources and unpredictable weather lead to poor accessibility of offshore wind farms, and operations can only be carried out in appropriate weather, resulting in large shutdown loss and high maintenance cost. Compared with onshore wind power, operation and maintenance cost of offshore wind farm is much higher, which can account for about $30 \%$ of the average energy cost [2]. Meanwhile, the current maintenance models are idealized or simple. In general, equipment status after maintenance is somewhere between perfect maintenance and minimum maintenance, that's to say, wind turbine status after preventative maintenance will be better than that before maintenance, but it can't return to the initial intact status $[3,4]$. In addition, once the maintenance engineering team arrives at the offshore wind farm, attention should also be paid to multiple wind turbine systems contained in the wind farm, and each offshore wind system also contains multiple 
equipment under simultaneous operation. Economic relevance differences between system and system, equipment and equipment should be comprehensively taken into consideration so that maintenance activities between systems and equipment in the wind farm can coordinate and cooperate with each other, so as to reduce outage loss and reduce fixed maintenance cost of the offshore wind farm [5].

In view of the complexity of the maintenance model for offshore wind farm, existing offshore wind farm maintenance methods, which can consider weather conditions, maintenance uncertainty and economic relevance of the maintenance, have achieved few researches progresses. Carlos et al. [6] optimized the maintenance cost for onshore wind farms based on the stochastic model. Laura and Vincente [7] analyzed the lifecycle cost for offshore wind farms, and Carroll [8] provided failure rate, repair time and unscheduled O\&M cost analysis of OWTs. Lu et al. [9] proposed a rolling horizon approach for OWTs, the maintenance planning can be updated to take short-term information into account, which could be changed with time, however, maintenance uncertainty is not considered in this study. Ding and Ting [10] compared imperfect maintenance and perfect maintenance based on replacement due to failure in preventive maintenance of wind turbines, and the study showed that imperfect maintenance method not only fitted engineering practice but also could save maintenance cost when compared with perfect maintenance mode based on replacement. Research by Huang et al. [11] showed that meaningful wave height is the main factor limiting landing system work and maintenance personnel landing, which determines the validity window of marine maintenance. Tian [12] developed a Condition based maintenance (CBM) strategy for WTs to optimize maintenance cost, and Lu et al. [13] optimized OWTs by the CBM strategy, the results showed that the CBM strategy is more effective than the time-based maintenance policies. Wu et al. [14] established a weather-based Markov maintenance model of an offshore wind system, estimated accessibility of offshore wind power maintenance and considered correlation between equipment maintenance, but the study object was not expanded to offshore wind farm, and maintenance imperfection in actual engineering was neglected. Hagen [15] proposed a multivariate Markov chain model for state estimation of sea conditions based on observation time sequences, weather conditions were expressed by wave height, wind velocity and wind direction, and maintenance strategies of the offshore wind farm were optimized. This model considered the influence of weather accessibility on the maintenance work, but neglected economic relevance between systems and equipment, and consequently, overall maintenance cost of the wind farm was not obviously reduced. Zhu et al. [16] proposed a failure model that included multiple failure modes with different failure consequences, logistic delays and weather conditions were also obstacles for performing maintenance activities, however, the research scheme had not been extended to offshore wind farms.

In this paper, the availability, uncertainty, economic relevance and outage loss of maintenance in practical offshore engineering are comprehensively considered, and the optimal maintenance scheme is formulated for the purpose of maximizing the power production of offshore wind farm. Section 2 gives concrete handling methods of imperfect equipment maintenance; In Section 3, considering the influence of weather environment accessibility on offshore wind turbine maintenance, based on the parameter estimation theory of L-moment, the expected waiting window time is calculated by the range of significant wave height in maintenance condition; In Section 4, a comprehensive maintenance model of offshore wind farm based on rolling horizon approach is established. The maintenance improvement factor, weather waiting time, downtime and other variables are introduced into the mathematical model. Taking optimal economical efficiency as the objective function, this model considers economic relevance between equipment and equipment, system and system during the maintenance process, which then improves accuracy of the decision-making model of total expected offshore wind farm maintenance cost; taking Dafengtian wind farm of Goldwind Technology Co., Ltd. as an example, Section 5 verifies the proposed maintenance optimization model, and results show that considering weather accessibility not only accords with actual offshore wind farm maintenance work, 
but moreover, compared with independent repair of wind turbines or equipment, the opportunistic grouping maintenance scheme can effectively reduce the cost, the reasonability and applicability of this model are verified.

\section{Handling Method of Imperfect Equipment Maintenance}

\subsection{Improved Factor Method}

The maintenance degree of equipment is usually uncertain. The assumption that the equipment is "as good as new" after maintenance is too ideal in practical engineering. The degradation system will unavoidably reduce reliability after preventive maintenance work, and in addition, the work time of the equipment after maintenance will present shortening trend with the system age.

Malik [17] once introduced the concept of age degradation factor in imperfect maintenance work: if $T_{i}$ and $\lambda_{i}(t)$ represent preventive maintenance cycle and failure rate of the equipment before the $i(t h)$ maintenance within the time $t \in\left(0, T_{i}\right)$, then the failure rate of the equipment after the $i(t h)$ maintenance within the time $t \in\left(0, T_{i}\right)$ will become $\lambda_{i}\left(t+a_{i} T_{i}\right)$, where $a_{i}$ is age degradation factor of the equipment in imperfect maintenance activity and it satisfies $0<a_{i}<1$, meaning that when the repair process is imperfect, the equipment state will be improved when compared with that before each maintenance, but it can't return to the initial serviceable condition. Nakagawa [18] proposed another model based on failure rate increase factor: failure rate of the equipment after the $i(t h)$ maintenance within the time $t \in\left(0, T_{i}+1\right)$ will become $b_{i} \lambda_{i}(t)$, where $b i$ is failure rate increase factor and it satisfies $b_{i}>1$, meaning that each preventive maintenance cost can make resetting of equipment failure rate function value into zero, but growth rate of the equipment failure rate function will be higher and higher.

From the description of the imperfect maintenance model, age degradation factor can consider the equipment attenuation process after each imperfect maintenance, and failure rate increase factor considers that growth rate of failure rate function of the equipment after each preventive maintenance becomes higher. In order to combine advantages of the two models, an improved factor method combining age degradation factor and failure rate increase factor was used in this paper to express imperfect equipment maintenance activity as shown in Figure 1.

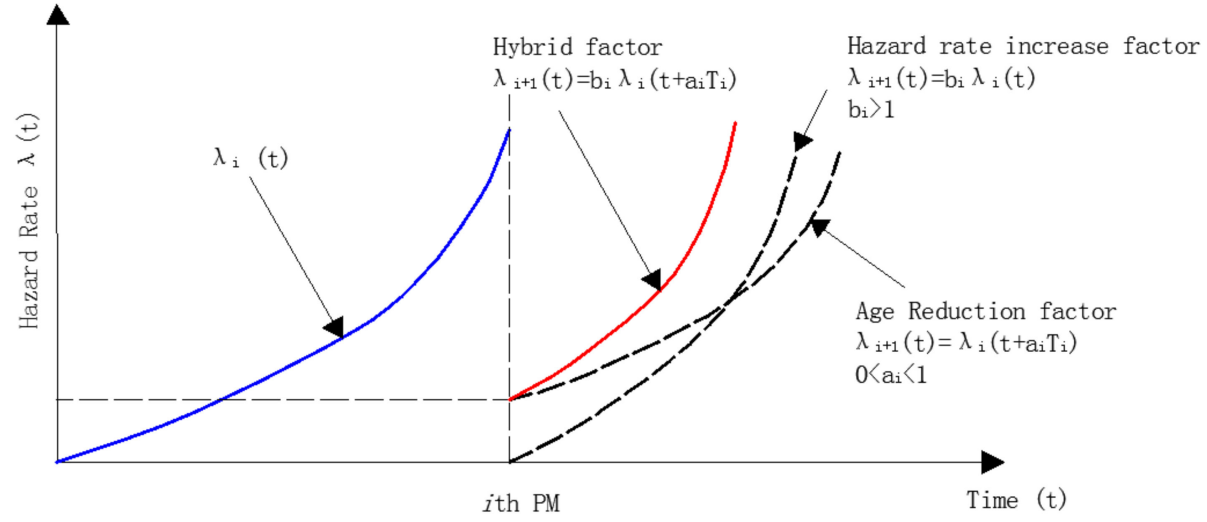

Figure 1. Improvement factor model for component failure rate.

In this case, the change of failure rate before and after the $i$ (th) equipment maintenance is as follows:

$$
\lambda_{i+1}(t)=b_{i} \times \lambda_{i}\left(t+\alpha_{i} \times T_{i}\right) t \in\left(0, T_{i+1}\right)
$$

where $0<a_{i}<1$ and $b_{i}>1$. The hybrid improved factor method can comprehensively consider the changes of failure rate and reliability of the equipment within each maintenance cycle in the imperfect maintenance activity.

In actual maintenance work, values of $a_{i}$ and $b_{i}$ are of randomness and uncertainty. Therefore, Monte Carlo algorithm was used in this paper to simulate equipment repair 
degree, and maintenance uncertainty was introduced into the optimization process of maintenance strategies.

\subsection{Monte Carlo Simulation}

Monte Carlo simulation is a method handling the random process. Generally, it can be expressed as a method to study quantitative events approximately through statistical sampling [19]. Therefore, it is a simulation to express uncertainty in a quantitative form. Monte Carlo simulation depends on concrete probability distribution form of input quantities to express their uncertainty. In this paper, Monte Carlo simulation is a process converting uncertainty $\left(a_{i}\right.$ and $\left.b_{i}\right)$ of maintenance degree into uncertainty of maintenance result, that is, if the input of maintenance degree is uncertain, the prediction of future maintenance result of equipment is uncertain.

In this paper, Monte Carlo simulation method is used for random sampling to convert uncertainty of $a_{i}$ and $b_{i}$ in the actual maintenance process into estimation of expected maintenance status. In order to complete this sampling process, first, we need to establish random probability density function for $a_{i}$ and $b_{i}$. Based on the existing statistical data, probability density function for $a_{i}$ and $b_{i}$ are lacked. At present, the normal distribution function has wide application in actual engineering. In order to simplify this sampling process, we assume that $a_{i}$ and $b_{i}$ obey the normal distribution and use them to complete the random sampling process.

It's assumed that values $a_{i}$ and $b_{i}$ of probability distribution in actual work complies with normal distribution as shown in Figure 2, where $a_{i} \sim N\left(0.005,0.002^{2}\right)$ and $b_{i} \sim N\left(1.005,0.001^{2}\right)$. On this basis, the equipment failure rate model based on improved factor method is established. The sampling results $\left(a_{i}\right.$ and $\left.b_{i}\right)$ are added into comprehensive maintenance optimization model of the offshore wind farm.

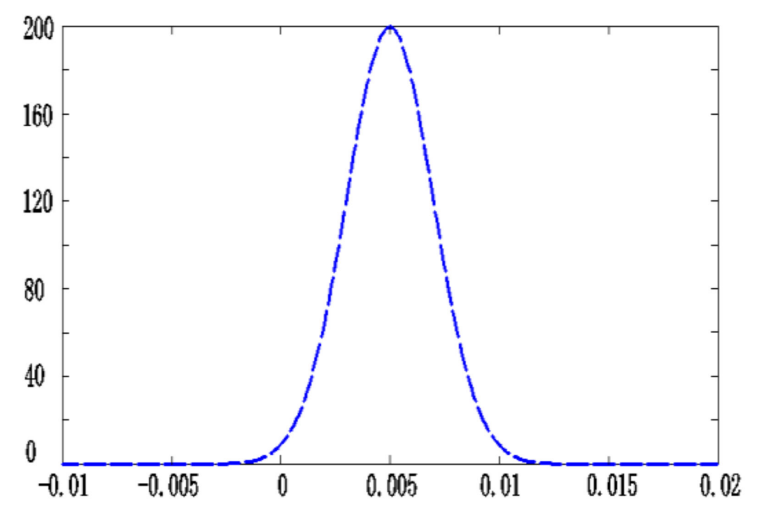

(a)

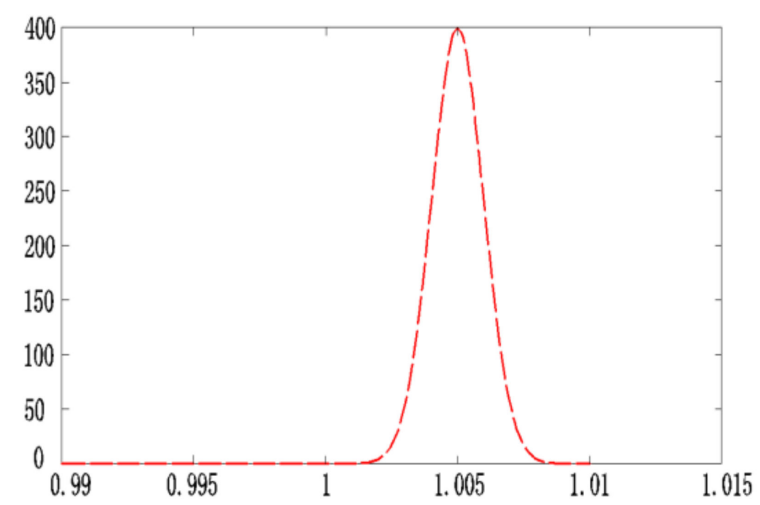

(b)

Figure 2. (a). Probability distribution of value $a_{i} ;(\mathbf{b})$. Probability distribution of value $b_{i}$.

\section{Offshore Wind Farm Accessibility Evaluation Method Considering Weather Window}

Maintenance personnel must be transported to the offshore wind farm under weather conditions with acceptable safety and economical efficiency. They should be placed in a proper working environment after ascending to the tower and safely arriving at wind turbine room. However, the weather window required for the offshore wind farm maintenance activity is quite complicated, wave height must be within effective wave height which can be borne by the maintenance ship, and it's required that maintenance work should be implemented under relatively peace sea conditions. Therefore, the influence of weather accessibility on the maintenance work as well as maintenance delay and wind turbine outage loss caused by severe weather should be fully considered during maintenance. 
Prediction of the weather window suitable for construction and maintenance is based on an analysis of statistical data (such as wave height and wind velocity). According to the present weather conditions, it's critical to accurately estimate the sustainability of operation conditions and waiting time of accessible sea conditions for offshore wind farm maintenance work. The maintenance scheme should be reasonably arranged according to the required time window, based on the weather window analysis results, and considering the sudden failure of wind turbines. According to European security system and restriction of sea conditions, the wave height which hinders wind turbine maintenance is usually within the range of 0.9-2.0 m. Reference [20] listed the influences of different wave heights on ship lease expense and its relationship with wind farm accessibility. Thus, it can be known that weather accessibility seriously affects operation safety and maintenance cost of the offshore wind farm. According to a statistical study by Goldwind Technology Offshore Wind Power Technology Institute, waves come from the northern direction and they are high in winter, and in summer, the waves are usually southward waves which are relatively smaller.

In this section, the mathematical concept and solving method of L-moment-based parameter estimation theory are expounded firstly. On this basis, weather window model is established to realize fitting the distribution of waiting windows, fitting accuracy is verified through a comparison with statistical data, and finally expected window waiting time is calculated. The expected waiting time obtained in this section will be introduced into the comprehensive offshore wind farm maintenance model in the next section.

\subsection{L-Moment-Based Parameter Estimation Theory}

The problem of probability distribution of hydrological eigenvalues is actually the problem of estimating the parameters of distribution function. Existing moment method (MOM), maximum likelihood method (MXL), curve-fitting method (FIT) and probability weight moment method (PWM) have large errors of sampling parameters due to "moment solving errors" of different degrees. L-moment, which is also one type of statistical parameter estimation method, derives from "probability weight moment" proposed by Hosking et al. [21]. It is linear combination of probability weight moment, so it's called L-moment. L-moment method is one of latest developments of the present hydrological frequency analysis and calculation. Its greatest feature is that it is not as sensitive as conventional moment to maximum (minimum) values of hydrological parameters, so estimated values of wave frequency curve parameters obtained based on L-moment method have smaller deviations than the values estimated by conventional moment.

Let random variable be $X$ and its value be $x$, the distribution function is $F(x)$, density function is $f(x)$, and probability weight moment defined by Greenwood is as follows:

$$
\alpha_{\gamma}=\int_{0}^{1} x(1-F(x))^{\gamma} d F(x) \quad \beta_{\gamma}=\int_{0}^{1} x F(x)^{\gamma} d F(x)
$$

It's always difficult to directly apply probability weight moment to explain meanings of several parameters such as scale and shape parameters. In fact, the above information can be expressed by linear combination of probability weight moment. For example, distribution scale parameters can be expressed by multiples of $\alpha_{0-} 2 \alpha_{1}$ or $2 \beta-{ }_{1} \beta_{0}$. On this basis, L-moment $\lambda_{\gamma}$ (L-Moment) $\lambda_{\gamma}=\int_{0}^{1} x P_{\gamma-1}^{*}(F(x)) d F(x)$ is defined as follows:

$$
\text { where } P_{\gamma}^{*}(u)=\sum_{k=0}^{\gamma} \frac{(-1)^{\gamma-k}(\gamma+k) !}{(k !)^{2}(\gamma-k) !} u^{k}
$$

The relationship between L-moment and probability weight moment is as follows:

$$
\lambda_{\gamma+1}=(-1)^{\gamma} \sum_{k=0}^{\gamma} \frac{(-1)^{r-k}(\gamma+k) !}{(k !)^{2}(\gamma-k) !} \alpha^{k}=\sum_{k=0}^{\gamma} \frac{(-1)^{\gamma-k}(\gamma+k) !}{(k !)^{2}(\gamma-k) !} \beta^{k}
$$


where the first four-order relational expressions of two moments are as follows:

$$
\begin{aligned}
& \lambda_{1}=\alpha_{0}=\beta_{0} \\
& \lambda_{2}=\alpha_{0}-2 \alpha_{1}=2 \beta_{1}-\beta_{0} \\
& \lambda_{3}=\alpha_{0}-6 \alpha_{1}+6 \alpha_{2}=6 \beta_{2}-6 \beta_{1}+\beta_{0} \\
& \lambda_{4}=\alpha_{0}-12 \alpha_{1}+30 \alpha_{2}-20 \alpha_{3}=20 \beta_{3}-30 \beta_{2}+12 \beta_{1}-\beta_{0}
\end{aligned}
$$

L-moment ratios are defined as: $\tau_{\gamma}=\lambda_{1} / \lambda_{2} \gamma=3,4$.

In addition, the definition reflects the coefficient of scale features namely $\tau_{2}=\lambda_{2} / \lambda_{1}$. $\tau_{3}$ reflects shape (skewness) feature, so it is called L-skewness; $\tau_{4}$ reflects kurtosis feature, so it is also called L-Kurtosis.

If the samples are $X_{1, n} \leq X_{2, n} \leq \ldots \leq X_{n, n}$, the computational formulas of sample moments $l_{1}, l_{2}, l_{3}$ corresponding to $\lambda_{1}, \lambda_{2}, \lambda_{3}$ in L-moment are as follows:

$$
\begin{gathered}
l_{1}=b_{0} ; l_{2}=2 b_{1}-b_{0} ; l_{3}=6 b_{2}-6 b_{1}+b_{0} ; \tau_{3}=l_{3} / l_{2} \\
b_{0}=n^{-1} \sum_{j=1}^{n} x_{j, n} \\
b_{1}=n^{-1} \sum_{j=2}^{n} \frac{j-1}{n-1} x_{j, n} \\
b_{2}=n^{-1} \sum_{j=3}^{n} \frac{(j-1)(j-2)}{(n-1)(n-2)} x_{j, n}
\end{gathered}
$$

Therefore, if samples $x_{1: n}, x_{2: n}, \ldots, x_{n: n}$ are given, $\lambda_{1}, \lambda_{2}, \lambda_{3}$ and $\tau_{1}, \tau_{2}, \tau_{3}, \tau_{4}$ can be estimated.

\subsection{Establishment of the Weather Window Model}

The operation and maintenance of offshore wind farms is affected by the significant wave height, wind speed, wind direction, etc., in which the significant wave height is the most critical factor to determine the operation and maintenance accessibility. Therefore, wave height is used as a marine environmental factor in this section to establish a weather window model.

The weather window can be defined as a period of weather conditions suitable for a particular offshore operation. Two key parameters, namely environment threshold and window length, need to be considered when looking at weather windows for offshore operation. The first parameter is the height of the wave that must be kept at the site, which is also defined as the wave height threshold $\left(h_{a c}\right)$. To determine the second parameter, sustainable data information should be found. Time persistence time $\left(T_{p}\right)$ of accessibility conditions is defined as the duration of significant wave height $\left(H_{s}\right)$ below wave height threshold $\left(h_{a c}\right)$, namely the persistence time of $\left(H_{s}<h_{a c}\right)$. Waiting time $\left(T_{w}\right)$ is considered to be the time required to wait for an accessible sea condition.

If $h_{1}, h_{2}, \ldots, h_{n}$ are $n$ wave heights which are smaller than $h_{a c}$ from samples, and operating conditions of offshore operation obey probability distribution $F\left(h_{a c}\right)$, then the probability for all continuous wave heights not to exceed $h_{a c}$ is $\left[F\left(h_{a c}\right)\right]^{\mathrm{n}}$, and the probability for maximum effective wave height $H_{\max }$ exceeding the designated wave height threshold level $h_{a c}$ is obtained through the following formulas:

$$
\begin{aligned}
& P\left(H_{\max }>h_{a c}\right)=1-G \\
& G=G\left(h_{a c}\right)=\left[F\left(h_{a c}\right)\right]^{n}
\end{aligned}
$$


when $H_{\max }>h_{a c}$, marine environmental conditions are not conducive to operation. Through a series of observations of these environmental conditions, if the $k$-th observed value does not exceed $h_{a c}$, then the probability of acceptable offshore operating conditions is as follows:

$$
P(K=k)=(1-G)^{k-1} \times G, k=1,2, \ldots
$$

where $K$ is a geometric random variable, and expected value $k$ (average value) is as follows:

$$
E(K)=\sum_{k=1}^{\infty} k \times(1-G)^{k-1} \times G
$$

where Equation (12) constitute an arithmetic geometric series: $E(K)=1 / G$.

$E(K)$ is the average number of waves with significant wave height $H s>$ wave height threshold $h_{a c}$. That is to say, marine condition formed by wave height threshold $h_{a c}$ is not good for the operation. Wave height is observed ever $3 \mathrm{~h}$ as the counting method until advantageous marine operating conditions are generated. Therefore, average waiting time $\left(T_{a w}\right)$ (by hour) of offshore operation is $3 \times E(K)$. Then, the daily average waiting time is obtained through the following formula:

$$
T_{a w}=3 \times E(K) / 24=E(K) / 8
$$

Equation (14) can be explained as the initial average waiting time appropriate for the weather window. If $Q($.$) is quantile function of F($.$) , then the wave height which can start$ an acceptable operating condition is:

$$
Q\left\{[1 / E(K)]^{1 / n}\right\}=Q\left[F\left(h_{a c}\right)\right]=h_{a c}
$$

\subsection{Optimal Fitting Distribution of Waiting Windows}

Significant wave height data of Portugal sea area of North Atlantic Ocean were collected from the Hipocas database [22] as shown in Figure 3, and a statistical analysis of weather windows was conducted. Generally, the significant wave height in the range of $1.5-3.5 \mathrm{~m}$ is considered as the environmental condition for offshore operation. In this study, the range of significant wave height $H_{S}$ represents the limit of environmental threshold $\left(h_{a c}\right)$.

Generalized extreme value (Gev), 3-parameter lognormal (LN3), Gumbel (Gum), 3parameter Weibull (Wei), Gamma (Gam) and generalized Pareto (GP3) were respectively fitted into significant wave height distribution in Portugal sea area in winter. Model parameters were estimated by L-moment method introduced in the previous section, and goodness of fit was determined through the $Z$ test within $95 \%$ confidence interval $(Z \leq 1.96)$. The $Z$-test values of the sample and statistical models are shown in Table 1.

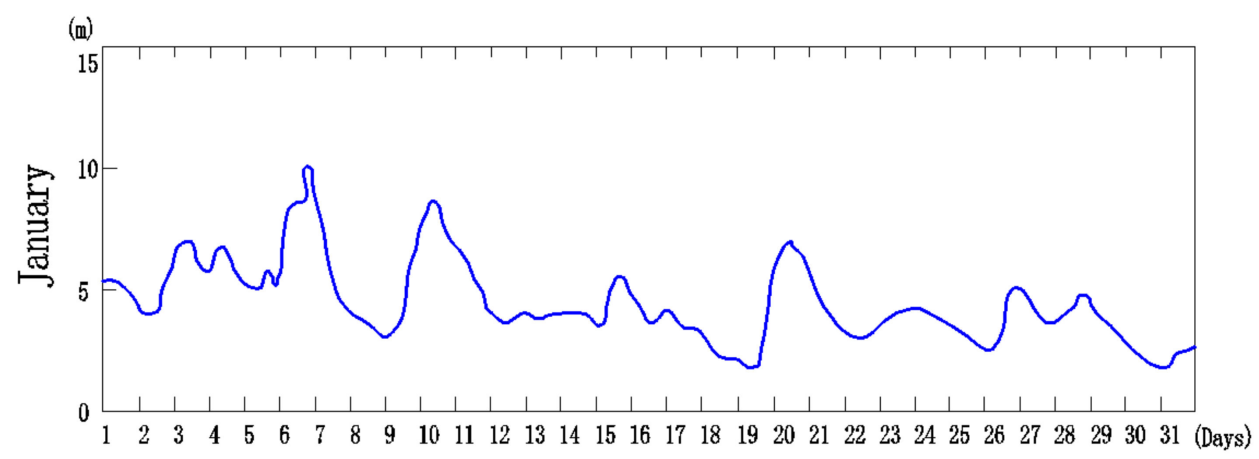

(a)

Figure 3. Cont. 


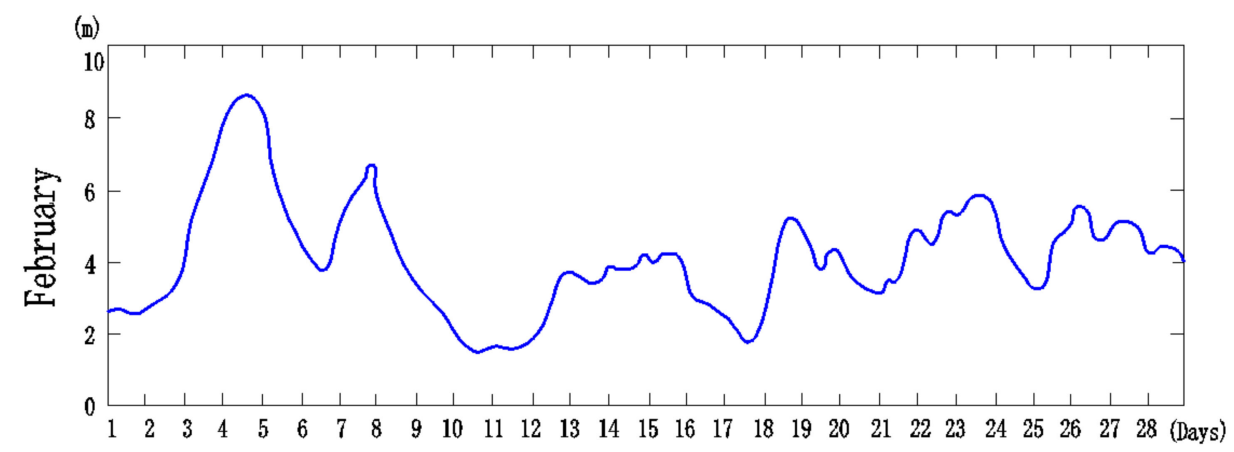

(b)

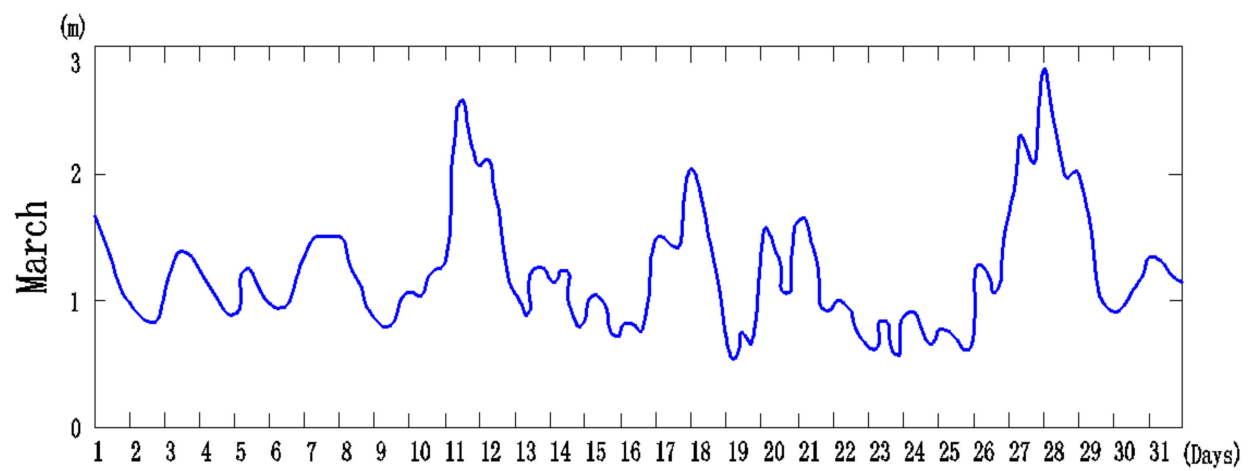

(c)

Figure 3. (a) Wave height data for Portuguese waters of the North Atlantic-1994-January; (b) Wave height data for Portuguese waters of the North Atlantic-1994-February; (c) Wave height data for Portuguese waters of the North Atlantic-1989-March.

Table 1. Z-test values of sample and model.

\begin{tabular}{cccccc}
\hline \multicolumn{7}{c}{ L-Moment Ratio } \\
\hline Statistical Model & $\boldsymbol{\lambda}_{\mathbf{1}}$ & $\boldsymbol{T}$ & $\boldsymbol{\tau}_{\mathbf{3}}$ & $\boldsymbol{\tau}_{\mathbf{4}}$ & Z-Test \\
\hline Sample & 3.625 & 0.933 & 0.214 & 0.151 & - \\
\hline Gev & 3.625 & 0.933 & 0.214 & 0.165 & 2.30 \\
\hline LN3 & 3.625 & 0.933 & 0.214 & 0.156 & 1.02 \\
\hline Gum & 3.626 & 0.933 & 0.176 & 0.149 & 0.27 \\
\hline Wei & 3.625 & 0.933 & 0.214 & 0.131 & 3.67 \\
\hline Gam & 3.624 & 0.932 & 0.161 & 0.128 & 3.18 \\
\hline GP3 & 3.625 & 0.933 & 0.214 & 0.081 & 7.97 \\
\hline
\end{tabular}

It can be seen that all statistical models have similar average value $\left(\lambda_{1}\right), L-C V(\tau)$ and L-skewness $\left(\tau_{3}\right)$ except for Gam and Gum. L-kurtosis $\left(\tau_{4}\right)$ estimated by Gum model is consistent with the sample value, $\mathrm{Z}$ test of Gum and LN3 indicates that the two models have achieved favorable goodness of fit with the sample. In order to verify the fitting accuracy of these statistical models, $Q-Q$ graphs of sample data quantiles and model quantiles within this range were drawn in this paper (as shown in Figure 4) to simulate cumulative distribution within 1.5-3.5 wave height range in offshore operation.

Similarly, in terms of $Q-Q$ graphs and their goodness of fit with the calibration line $(\mathrm{x}=\mathrm{y})$, quantile functions of Gum and LN3 are the most effective models generating $H s$ distribution in sample data. According to $Z$ tests and $Q-Q$ graphs, $Z$ tests guarantee goodness of fit of Gum and LN3 models for wave height distribution in the sea area of 
Portugal in winter, and the $Q-Q$ graphs confirms that these models are also suitable for simulating the wave height distribution. Therefore, Gum and LN3 were selected in this paper as the optimal universal models of sample data.

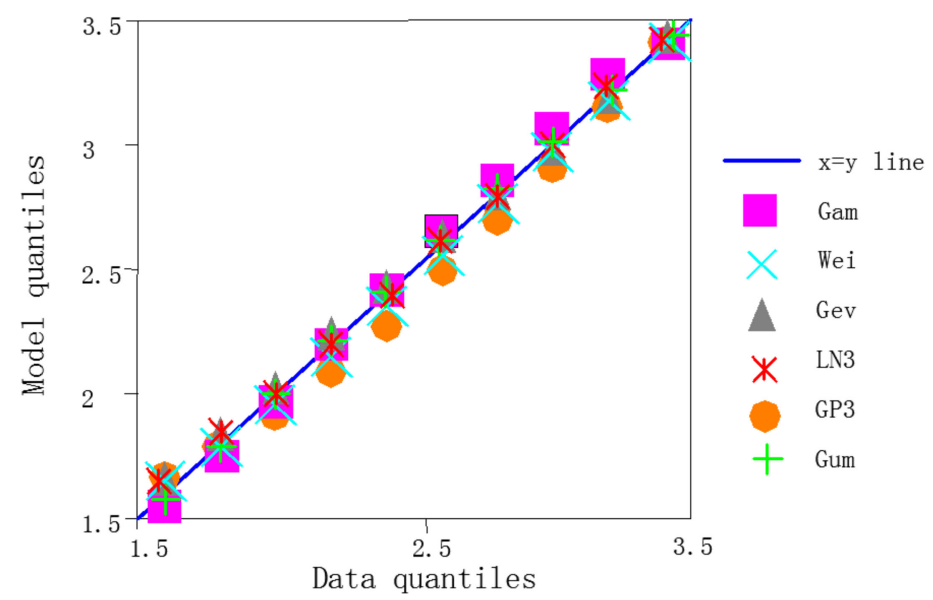

Figure 4. $Q-Q$ plot in the range 1.5-3.5 for data and model quantiles.

\subsection{Estimation of Waiting Windows}

In order to estimate average waiting time $\left(T_{a w}\right)$ for accessible sea conditions in Equation (14), Gum and $L N 3$ were used to fit the wave height number $n$ in Equation (11) which is smaller than the wave height threshold $\left(h_{a c}\right)$ in the range of $1.5-3.5 \mathrm{~m}$. Figures 5 and 6 shows $n-h_{a c}$ functional relationships obtained by fitting of distribution of $L N 3$ and Gum models.

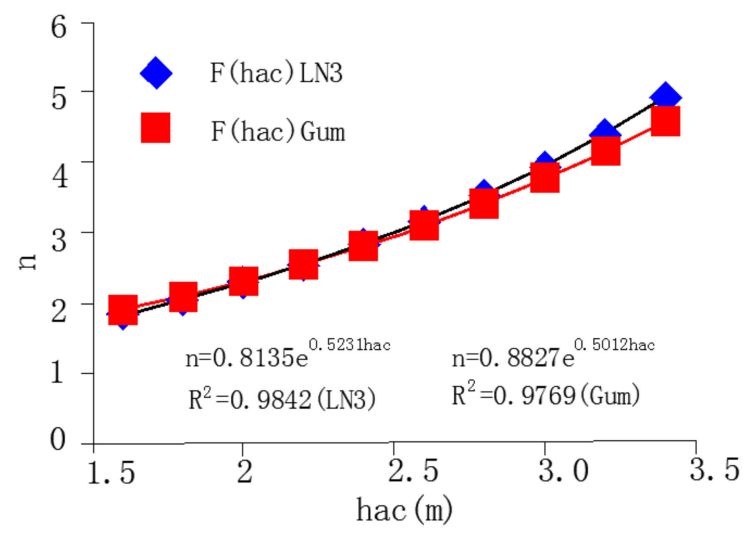

Figure 5. Fitting results between waiting weather window duration and threshold heights $h_{a c}$.

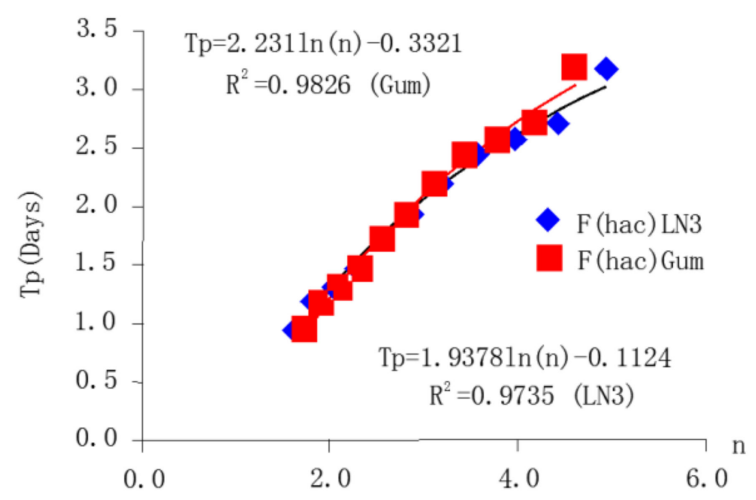

Figure 6. Fitting results between estimated weather window duration and threshold heights $h_{a c}$. 
The results show that during the weather window waiting time, number $n$ of wave heights smaller than $h_{a c}$ and wave height threshold $\left(h_{a c}\right)$ conform to an exponential relationship (goodness of fit: 0.9842); during the weather window persistence time, number $n$ of wave heights smaller than $h_{a c}$ and wave height threshold $\left(h_{a c}\right)$ conform to a logarithmic relationship (goodness of fit: 0.9826). Probability histogram for wave heights not exceeding $H_{s}$ in winter generated by Gum and LN3 models is shown in Figure 7.

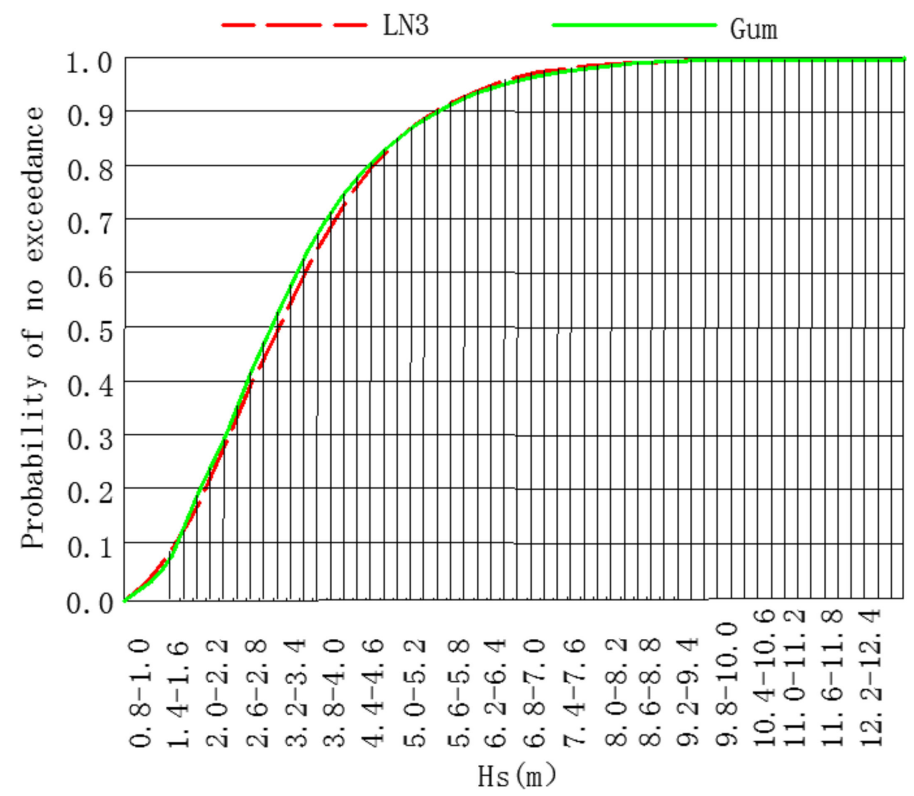

Figure 7. Probability of no exceedance for $H_{s}$ using LN3 and Gum.

According to the percentage of wave heights not exceeding threshold $h_{a c}$ in winter, waiting time $T_{w}$ and persistence time $T_{p}$ can be estimated for given $h_{a c}$, as shown in Table 2 .

Table 2. Waiting time and persistence (in days) of threshold heights (1.4-3.4 m).

\begin{tabular}{ccc}
\hline$h_{a c}$ & $\boldsymbol{T}_{w}$ & $\boldsymbol{T}_{\boldsymbol{p}}$ \\
\hline 1.4 & 0.75 & 5.61 \\
\hline 1.6 & 0.94 & 3.47 \\
\hline 1.8 & 1.05 & 2.48 \\
\hline 2 & 1.19 & 2.05 \\
\hline 2.2 & 1.38 & 1.81 \\
\hline 2.4 & 1.55 & 1.41 \\
\hline 2.6 & 1.76 & 1.12 \\
\hline 2.8 & 1.96 & 0.96 \\
\hline 3 & 2.06 & 0.84 \\
\hline 3.2 & 2.18 & 0.63 \\
\hline 3.4 & 2.55 & 0.60 \\
\hline
\end{tabular}

\section{Comprehensive Offshore Wind Farm Maintenance Strategies Based on Rolling Horizon Approach}

In order to solve the problem of maintenance economic relevance among various equipment and the availability of each wind turbine in the whole offshore wind farm, it can be considered to evaluate the working status of other wind turbines and other equipment when carrying out maintenance work on a certain equipment for a certain wind turbine, and repair other wind turbine equipment close to the reliability threshold in advance, so 
as to reduce the maintenance frequency of the whole offshore wind farm and reduce its overall maintenance cost.

In this section, we will consider the economic relevance of the maintenance process and establish an opportunistic grouping optimization model for offshore wind farms based on rolling horizon approach. First, we calculate the maintenance reliability threshold of each equipment. For each equipment, there is a dynamic reliability change based on the maintenance process. We introduce the maintenance improvement $a_{i}$ and $b_{i}$ mentioned in Section 2 into the failure rate function, as shown in Equation (17). In the process, the average maintenance cost of each equipment $\left(E C_{m i}\right)$ can be calculated by Equation (20). Second, offshore wind form opportunistic maintenance model is established considering weather effect and economic relevance of the maintenance process. We introduce the average weather waiting time $T_{a w}$ mentioned in Section 3 and maintenance cycle $\Delta t_{m i, j}$ into the cumulative time variable calculation, as shown in Equations (21) and (22) We can get the economic loss of equipment $i$ due to waste of residual service life in this opportunistic maintenance by multiplying average maintenance cost and cumulative time variable, as shown in Equation (27) Finally, in the opportunity group optimization model of offshore wind farm, the economic positive and negative correlation of various combination modes of all equipments are analyzed, and the optimal maintenance combination scheme is selected. The dynamic planning process of opportunistic maintenance strategies of the offshore wind farm considering weather effect can be expressed by Figure 8 .

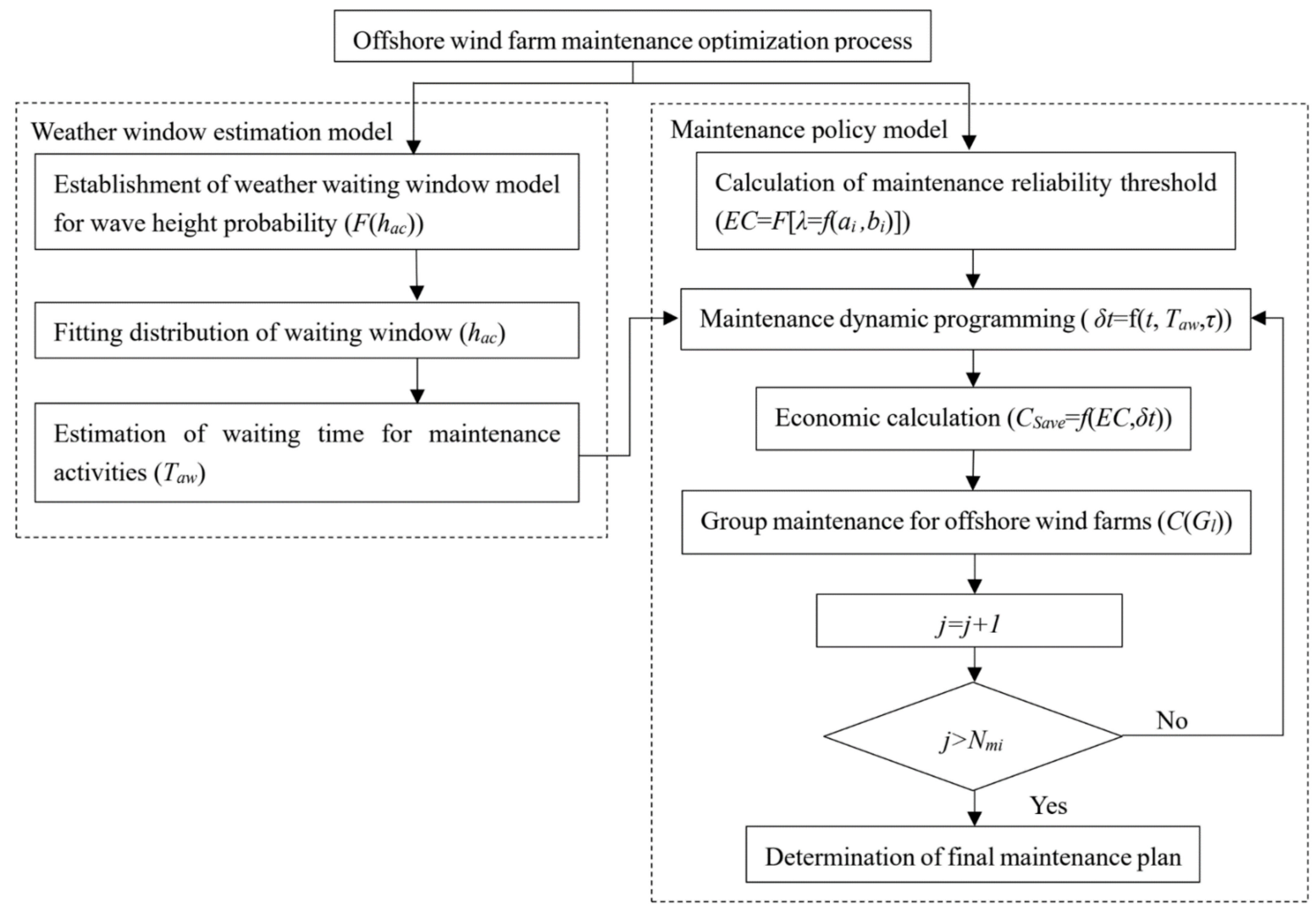

Figure 8. Dynamic procedure of opportunistic maintenance optimization for offshore wind farm.

\subsection{Assumptions}

The following assumption should be made in order to establish a comprehensive maintenance model for the offshore wind farm with multiple wind turbines and equipment in this paper:

(1) The offshore wind form consists of $m$ wind turbines and $n$ mutually independent equipment, each wind turbine and each equipment have two states-working state 
and outage state, and all components are under outage state during each maintenance process (preventive maintenance and fault maintenance).

(2) Equipment failure rate of the equipment satisfies a Weibull distribution, which can be expressed as:

$$
\lambda_{i}(t)=\frac{\beta_{i}}{\alpha_{i}} \times\left(\frac{t}{\alpha_{i}}\right)^{\beta_{i}-1}
$$

(3) When a wind turbine equipment reaches its reliability threshold $R_{m i}$, then preventive maintenance of the equipment should be carried out to avoid degradation and failure. After the preventive maintenance work is completed, the equipment will restart a new round of the failure and degradation process.

(4) If the equipment goes through a sudden failure before the preventive maintenance, then fault maintenance can make the equipment reenter working state while its failure rate is not changed.

(5) The outage loss of a sudden failure of the offshore wind power system is high, so fault maintenance cost is higher than planned preventive maintenance.

(6) When a wind turbine equipment is put under opportunistic maintenance, then all equipment of this wind turbine involved in this maintenance will be considered having the same outage time $\tau_{\text {outmi }}$ and outage loss $C_{\text {outmd }}$, namely $\tau_{\text {outmi }}=\ldots=$ $\tau_{\text {outmi }_{n}}=\tau_{\text {outmi }}, C_{\text {outmd }_{1}}=\ldots=C_{\text {outmdn }}=C_{\text {outmd }}$.

\subsection{Calculation of Maintenance Reliability Threshold}

Based on the above hypotheses, rolling horizon approach was improved and extended, and a dynamic maintenance model of multiple wind turbines and multiple equipment was established. As for maintenance degree, the handling method for imperfect equipment maintenance mentioned in Section 2 was used in this paper, therefore, the failure rate function of the $i$-th equipment on the $m$-th wind turbine before and after the $j$-th preventive maintenance can be expressed as below:

$$
\lambda_{m i, j+1}(t)=b_{m i, j} \times \lambda_{m i, j}\left(t+\alpha_{m i, j} \times \Delta t_{m i, j}\right)
$$

where $\lambda_{m i, j}(t)$ is the failure rate function of the $i$-th equipment on the $m$-th wind turbine before the $j$-th preventive maintenance; $\Delta t_{m i, j}$ is the $j$-th maintenance cycle of the $i$-th equipment on the $m$-th wind turbine and aging factors satisfy $0<\alpha_{m i}<1$ and $b_{m i}>1$.

As for preventive maintenance, when the $i$-th equipment on the $m$-th wind turbine reaches maintenance reliability threshold $R_{m i}$, preventive maintenance will be implemented, and at this time, the following equation holds:

$\exp \left[-\int_{0}^{\Delta t_{m 1, j}} \lambda_{m 1, j}(t) d t\right]=\exp \left[-\int_{0}^{\Delta t_{m 2, j}} \lambda_{m 2, j}(t) d t\right]=\ldots=\exp \left[-\int_{0}^{\Delta t_{m i, j}} \lambda_{m i, j}(t) d t\right]=R_{m i}$

Equation (18) can also be expressed as below:

$$
\int_{0}^{\Delta t_{m 1, j}} \lambda_{m 1, j}(t) d t=\int_{0}^{\Delta t_{m 2, j}} \lambda_{m 2, j}(t) d t=\ldots \int_{0}^{\Delta t_{m i, j}} \lambda_{m i, j}(t) d t=-\ln R_{m i}
$$

where $\int_{0}^{\Delta t_{m i, j}} \lambda_{m i, j}(t) d t$ is cumulative failure risk of the $i$-th equipment on the $m$-th wind turbine within the $j$-th maintenance cycle, and the times of unplanned accidental equipment failure is equal to the times of corresponding fault maintenance, namely both being $-\ln R_{m i}$.

It's assumed that within the fixed working time $T$, the times of aperiodic imperfect maintenance of the $i$-th equipment on the $m$-th wind turbine is $N_{m i}$, then average maintenance cost of the $i$-th equipment on the $m$-th wind turbine should be:

$$
E C_{m i}=\frac{N_{m i}\left[C_{\text {fixed }}+\left(C_{A C(m i)}+C_{\text {out }(m i)} \times T_{a w}\right) \times\left(-\ln R_{m i}\right)+C_{P M(m i)}^{\prime}+C_{\text {out }(m i)} \tau_{\text {outmi,j }}\right]}{\sum_{j=1}^{N_{i}}\left(\Delta t_{m i, j}+\tau_{\text {outmi }, j}+T_{a w}\right)}
$$


where $C_{\text {fized }}$ is the fixed expense of personnel organizing the maintenance (including expense of ships and maintenance personnel); $\Delta t_{m i, j}$ is the preventive maintenance cycle of the $i$-th equipment on the $m$-th wind turbine; $\tau_{o u t m i, j}$ is outage time needed by this preventive maintenance; $T_{a w}$ is weather window waiting time; $C_{A C(m i)}$ is economic loss of an accidental failure; $C_{P M(m i)}$ and $C_{\text {out }(m i)}$ represent expense of one preventive maintenance action of equipment $i$ and the outage loss of each wind turbine per unit time, respectively; $C_{P M(m i)}^{\prime}$ is the imperfect maintenance cost of one piece of wind turbine equipment, and its value is related to $\alpha_{m i}, b_{m i}$ and $C_{P M(m i)}$, which can be expressed as $C_{P M(m i)}^{\prime}=\left(1-\alpha_{m i}\right)^{2}$ $\times\left(1-b_{m i}\right)^{2} \times C_{P M(m i)}$. The interval $\Delta t_{m i, j}$ of preventive maintenance is a function of the reliability threshold $R_{m i}$ and can be obtained through Equation (20). By solving the minimum value of $E C_{m i}$, the optimal reliability threshold of equipment $i$ in different wind turbines can be obtained, and determination of $R_{m i}$ value is the basis for the next-step establishment of the offshore wind farm opportunistic maintenance model.

\subsection{Offshore Wind Farm Opportunistic Maintenance Model Considering Weather Effect}

$t_{m i, j}$ is set as the $j$-th preventive maintenance time of the $i$-th equipment on the $m$-th wind turbine; $\Delta t_{m i, j}$ is maintenance cycle; $T_{a w}$ is average waiting time of weather window; $T_{P}$ is average wave height persistence time in maintenance operation, and then $t_{m i, j}$ can be expressed as:

$$
\begin{gathered}
t_{m i, 1}=t_{\text {begin }}+\Delta t_{m i, 1}+T_{a w}\left(T_{p} \geq \Delta t_{m i, 1}\right) \\
t_{m i, j}=t_{m i, j-1}+\Delta t_{m i, j-1}+T_{a w}+\tau_{\text {outmi }, j-1}\left(j>1, T_{p} \geq \Delta t_{m i, j-1}\right)
\end{gathered}
$$

where $\tau_{\text {outmi,j }}$ is the outage time needed by the $j$-th maintenance cycle of the $i$-th equipment on the $m$-th wind turbine. According to Equations (21) and (22), the time of all previous preventive maintenances of wind turbines within the total maintenance cycle of the wind farm can be determined.

For an offshore wind farm containing $m$ offshore wind turbines with each wind turbine containing $n$ equipment, when an equipment (set as $k$ ) of one wind turbine is under preventive maintenance, equipment $i$ on this wind turbine or other wind turbines will have an opportunity to accept opportunistic maintenance within the maintenance time $\tau_{\text {outmk }, j}$. If opportunistic maintenance is carried out at this moment, then corresponding formula of maintenance economical efficiency can be written as follows:

$$
C_{\text {Save }(m i, m k, j)}=C_{f i x e d}+C_{\text {OuT }(m i, m k, j)}+C_{A C(m i, m k, j)}-C_{P M(m i, m k, j)}
$$

where $C_{\mathrm{OUT}}(m i, m k, j)$ is the outage loss reduction of equipment $i$ and $k$ under simultaneous maintenance and it can be expressed as follows:

$$
C_{\text {OuT }(m i, m k, j)}=C_{\text {out }(m i)} \times \tau_{\text {outmi, } m k \in \min }
$$

where $\tau_{m i, m k \in \min }$ is the shortest outage time needed by preventive maintenance of equipment $i$ or $k . C_{M(m i, m k, j)}$ is preventive maintenance-reduced economic loss due to accidental failure of equipment $i$, and it can be written as:

$$
C_{A C(m i, m k, m j)}=\left[\left(-\ln R_{m i}\right)-\left(-\ln R_{m i, m k}\right)\right] C_{A C(m i)}
$$

where $R_{m i, m k}$ is reliability of equipment $i$ when it is maintained simultaneously with equipment $k$.

It's noteworthy that the maintenance time of each equipment will be continuously updated due to preventive and opportunistic maintenance. $t_{m i, j}$ is set as initial preventive maintenance time of equipment $i$ and $\Delta t_{i, j}^{\prime}$ is preventive maintenance time after updating, and then cumulative time variable quantity can be written as:

$$
\delta t_{m i, k}=\sum_{j=1}^{M}\left(t_{m i, j}-t_{m i, j}^{\prime}\right)=\sum_{j=1}^{M}\left(t_{m i, j-1}+N_{m i} T_{a w}-t_{m i, j-1}^{\prime}-N_{m i}^{\prime} T_{a w}\right) M=\min \left\{N_{m i}, N_{m i}^{\prime}\right\}
$$


where $N_{m i}$ is the times of originally planned preventive maintenance of each wind turbine equipment; $N_{m i}^{\prime}$ is the times of planned preventive maintenance after updating of each wind turbine equipment, and at the time, the economic loss of equipment $i$ due to waste of residual service life in this opportunistic maintenance can be expressed as follows:

$$
C_{P M(m i, m k, j)}=E C_{m i} \times \delta t_{m i, k}
$$

Through Equations (26) and (27), we can get the amount that can be saved when the equipment $i$ and equipment $k$ in the same or different wind turbines are maintained at the same time. If $C_{\text {Save }(m i, m k, j)}>0$, this opportunistic maintenance generates positive economic relevance, which is good for cost reduction, and equipment $i$ and $k \mathrm{~d}$ can be simultaneously maintained; if $C_{\text {Save }(m i, m k, j)}<0$, this opportunistic maintenance generates negative economic relevance, which is to the disadvantage of cost reduction, and equipment $i$ should not be maintained in advance.

\subsection{Opportunistic Grouping Optimization Model of the Offshore Wind Farm}

On the basis of determining the calculation method of opportunistic maintenance economy considering weather window, overall calculation of all wind turbines and all equipments in the offshore wind farm should be carried out, positive and negative economic relevance values of all the combinations modes should be analyzed, and the optimal combination scheme should be selected. Maintenance combination mode of the offshore wind farm is set as the set $G$, and in each outage maintenance, its subsets $G_{1}, G_{2} \ldots G_{1}$ satisfy:

$$
\begin{aligned}
& G_{p} \cap G_{q}=\varnothing \quad p \neq q \\
& G_{1} \cup G_{2} \cup \ldots \cup G_{l}=G
\end{aligned}
$$

When equipment $k$ is the first one to reach reliability threshold for preventive maintenance, all opportunistic maintenance combination modes at the time are solved and maintenance cost surplus $C\left(G_{l}\right)$ is calculated:

$$
C\left(G_{l}\right)=\sum_{i \in G_{l}} C_{\text {save }(m i, m k, j)} \quad i \neq k
$$

Through the comparison of $C\left(G_{l}\right)$ values under different combination modes, the combination corresponding to the maximum value is regarded as the optimal maintenance scheme.

\section{Calculation and Analysis}

\subsection{Site Selection and Maintenance of Dafengtian Wind Farm of Goldwind Technology}

Since its establishment, Goldwind Technology (Yancheng City, Jiangsu Province, China) has operated global wind power sites with an installed capacity exceeding $44 \mathrm{GW}$, 28,500 wind turbine sets and over 19,000 wind power generating sets, and it has been operating stably in nearly 20 countries located in six continents around the globe. The Dafengtian offshore wind farm is owned by Goldwind Technology Co., Ltd., located in Yancheng City, Jiangsu Province, which started operations in 2015.

According to operation and maintenance cost data provided by Goldwind Technology Co., Ltd., the Dafengtian offshore wind farm has $802.5 \mathrm{MW}$ offshore wind turbines with a total power of $200 \mathrm{MW}$, or $200,000 \mathrm{KW}$. The total investment on this wind farm is RMB 3.3 billion, it's planned to be put into operation for 25 years, the operation height of the wind turbines is $90-100 \mathrm{~m}$, and the annual average wind velocity is $6.7 \mathrm{~m} / \mathrm{s}$. This wind farm uses scheduled maintenance mode with a fixed cycle, and the planned input maintenance cost is RMB 150/1 kW/year, or RMB 30 million/year. The wind farm has 20 maintenance personnel at present, and the proportions of the maintenance cost are shown in Figure 9. 


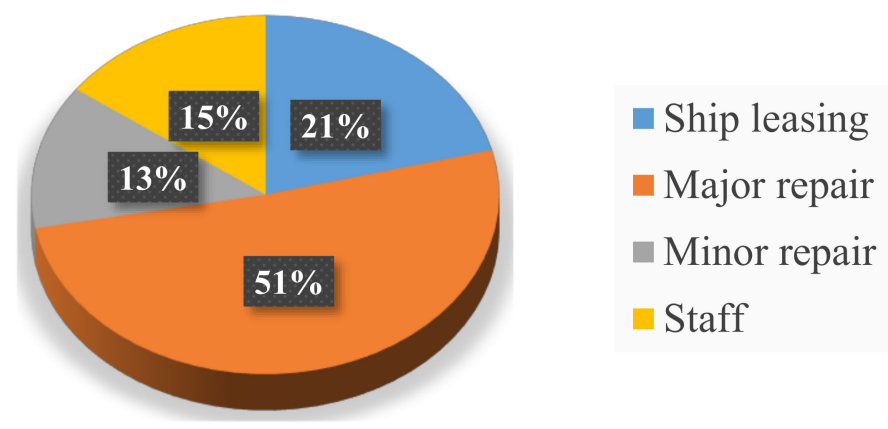

Figure 9. Proportion of maintenance cost for Dafengtian offshore wind farm.

In fact, the Dafengtian offshore wind turbine uses direct drive technology and does not need gearbox equipment, so this paper selects four main pieces of equipment with the highest maintenance cost, namely rotor, generator, pitch and brake, as the calculation and research objects, the proportions of average failure rates of the four main equipment are shown in Figure 10.

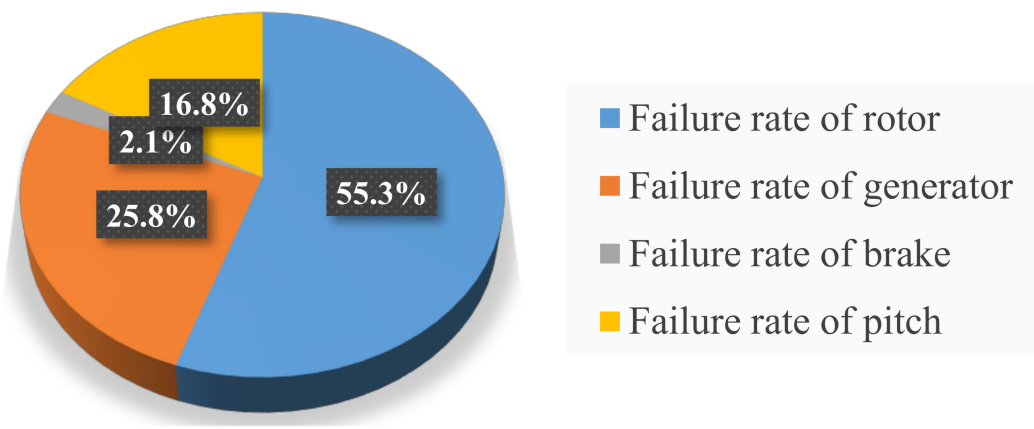

Figure 10. Proportion of failure rate for main components.

During the calculation process of outage losses, as wind turbines operate under a rated power of $2.5 \mathrm{MW}$, the electric charge (tax included) is RMB 0.5/h according to the average market price, and then the outage loss is calculated as $C_{\text {OUT }(m i)}=2500 \times 0.5 \times 24=\mathrm{RMB}$ $30,000 / \mathrm{d} / \mathrm{ea}$. According to the statistics, maintenance cost and outage time of each equipment of offshore wind turbines are shown in Table 3. Offshore wind farm maintenance activities must have a ship or a sophisticated controllable platform system which matches the weather conditions, and different weather conditions are corresponding to different ship lease expenses, which influences fixed maintenance $\operatorname{cost} C_{\text {fixed }}$ (including personnel organization and ship lease) as shown in Table 4. In addition, as both Yancheng City, Jiangsu Province where the Dafengtian offshore wind farm is located and Portugal's sea area in the North Atlantic Ocean both belong to a subtropical climate, so weather windows were established for Dafengtian offshore wind farm in this paper based on statistical wave data information of the Portuguese sea area of the North Atlantic Ocean [23], maintenance wave height threshold was taken as $2 \mathrm{~m}$, and window waiting time was calculated and estimated. As for imperfect equipment maintenance, the improved factor method proposed in Section 2 was used to consider equipment degradation process with maintenance, and Monte Carlo method was used to randomly extract aging degradation factor $\alpha_{i}$ and failure rate increase factor $b_{i}$ to simulate uncertainty of actual maintenance quality.

\subsection{Calculation of Dafengtian Wind Farm Maintenance Scheme}

In this paper, the dynamic programming calculation method in Section 4 is used to calculate and analyze the maintenance scheme of 80 offshore wind turbines in Dafengtian offshore wind farm, considering the weather accessibility, incomplete maintenance, outage loss and economic relevance of maintenance. The simulation time is 730 days 
(2 years). Among them, the opportunistic group maintenance scheme for four main pieces of equipment of five offshore wind turbines is shown in Figure 11.

Table 3. Critical components of OWTs and cost parameters. (¥/year).

\begin{tabular}{|c|c|c|c|c|}
\hline Component & $\begin{array}{c}\text { Cost of Fault Maintenance } \\
C_{A C(m i)}\end{array}$ & $\begin{array}{c}\text { Cost of Preventive Maintenance } \\
C_{P M(m i)}\end{array}$ & $\begin{array}{c}\text { Downtime Loss } \\
C_{\text {OUT }(m i)}\end{array}$ & $\begin{array}{c}\text { Maintenance Time } \\
\tau_{\text {outmi } j}\end{array}$ \\
\hline Rotor & 30,000 & 3300 & 30,000 & 4 \\
\hline Generator & 25,000 & 1250 & 30,000 & 3 \\
\hline Pitch & 19,000 & 2100 & 30,000 & 2 \\
\hline Brake & 23,000 & 2600 & 30,000 & 2 \\
\hline
\end{tabular}

Table 4. Fixed maintenance costs under different weather conditions.

\begin{tabular}{ccc}
\hline Weather Conditions & Fixed Cost $\boldsymbol{C}_{\mathbf{0}} \mathbf{( 1 0 , 0 0 0} ¥ /$ Year $)$ & Applicable Wave Height $(\mathbf{m})$ \\
\hline 1 & 200 & $<1.2$ \\
\hline 2 & 350 & $<1.5$ \\
\hline 3 & 500 & $<2.0$ \\
\hline
\end{tabular}

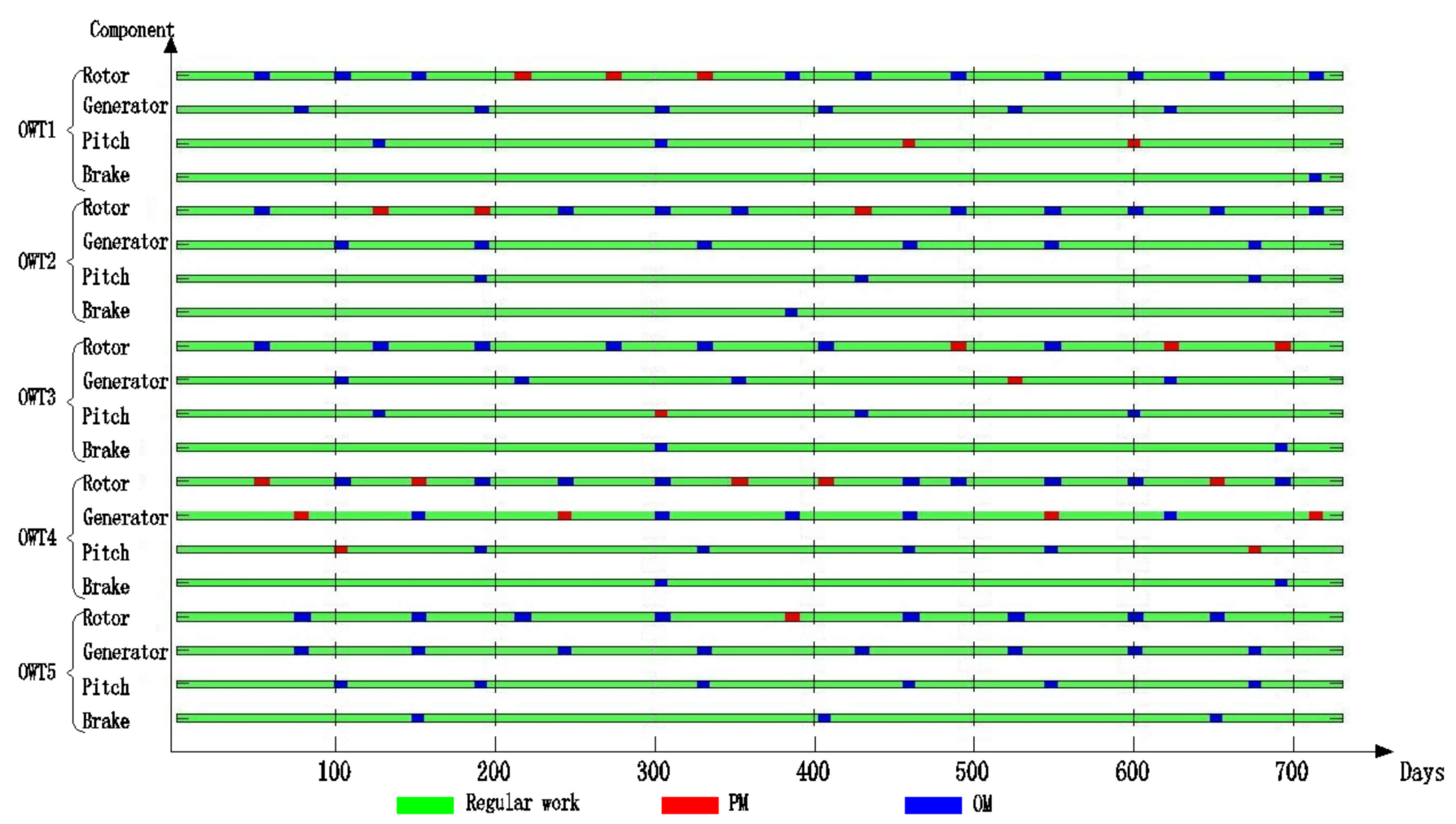

Figure 11. Opportunity group maintenance plan for 4 main equipment of 5 OWTs.

The calculation results show that rotor is the equipment with the highest frequency of preventive maintenance, and this provides many advanced maintenance opportunities for other offshore wind turbine equipment. The reason is that the failure probability of the rotor is high, and the speed to reach the reliability threshold is the fastest after a maintenance. When the rotor first reaches the reliability threshold and carries out preventive maintenance, it also provides maintenance opportunities for other equipment, thus saving the fixed cost. Maintenance times of main equipment for each wind turbine is shown in Table 5. During the two-year planned maintenance cycle, 20 main pieces of equipment of five offshore wind turbines have 25 instances of preventive maintenance and 99 maintenance opportunities. It is worth noting that all maintenance activities of the brakes are completed by opportunistic 
maintenance provided by other equipment, which indicates that the brake equipment using the maintenance model proposed in this paper can save more maintenance costs, and the optimization effect is obvious. In addition, incomplete maintenance is considered in this paper, so the maintenance time interval is aperiodic. For example, in the first maintenance scheme for wind turbine rotor, the 3rd, 4th and 5th maintenance time are $148 \mathrm{~d}, 213 \mathrm{~d}$ and $327 \mathrm{~d}$, respectively, and the maintenance time intervals are $65 \mathrm{~d}$ and $57 \mathrm{~d}$. Considering the influence of incomplete maintenance, the maintenance time gradually decreases. As mentioned earlier, maintenance activities are usually imperfect, and the health status of equipment will decline with the increase of maintenance activities. Therefore, the practical application of incomplete maintenance considered in this paper is more realistic.

Table 5. The maintenance times of the main equipment for 5 OWTs.

\begin{tabular}{|c|c|c|c|}
\hline \multirow{2}{*}{ NO. OWTs. } & \multirow{2}{*}{ Component } & \multicolumn{2}{|c|}{ Number of Maintenance } \\
\hline & & PM & OM \\
\hline \multirow{4}{*}{1} & Rotor & 3 & 10 \\
\hline & Generator & 0 & 6 \\
\hline & Pitch & 2 & 2 \\
\hline & Brake & 0 & 1 \\
\hline \multirow{4}{*}{2} & Rotor & 3 & 9 \\
\hline & Generator & 0 & 6 \\
\hline & Pitch & 0 & 3 \\
\hline & Brake & 0 & 1 \\
\hline \multirow{4}{*}{3} & Rotor & 3 & 7 \\
\hline & Generator & 1 & 4 \\
\hline & Pitch & 1 & 3 \\
\hline & Brake & 0 & 2 \\
\hline \multirow{4}{*}{4} & Rotor & 5 & 9 \\
\hline & Generator & 4 & 5 \\
\hline & Pitch & 2 & 4 \\
\hline & Brake & 0 & 2 \\
\hline \multirow{4}{*}{5} & Rotor & 1 & 8 \\
\hline & Generator & 0 & 8 \\
\hline & Pitch & 0 & 6 \\
\hline & Brake & 0 & 3 \\
\hline
\end{tabular}

\subsection{Analysis of Economical Efficiency}

Table 6 shows the cost surplus of comprehensive maintenance strategies of five offshore wind turbines in the Dafengtian offshore wind farm. During the implementation process of the comprehensive maintenance model proposed in this paper, the total saved cost was $1,579,128 ¥$ and average daily maintenance cost was reduced by $2163 ¥$ during the whole 2-year maintenance cycle (2015-2017). Results show that under a reasonable grouping situation, comprehensive maintenance strategy proposed in this paper can save the maintenance cost $42.11 \%$ for 5 offshore wind turbines in Dafengtian wind farm when compared with the maintenance based on fixed time. Among them, five offshore wind turbines obtained many opportunistic maintenance opportunities at $148 \mathrm{~d}, 456 \mathrm{~d}$ and $597 \mathrm{~d}$, and each offshore maintenance cost surplus was over 100,000 $¥$. 
Table 6. Maintenance schedule and cost savings of five OWTs for the Dafengtian farm.

\begin{tabular}{|c|c|c|c|c|c|c|c|c|c|c|c|c|c|c|c|c|c|c|c|c|c|c|}
\hline \multirow{2}{*}{\multicolumn{2}{|c|}{$\begin{array}{l}\text { NO. OWTs. } \\
\text { Component }\end{array}$}} & \multicolumn{4}{|c|}{ OWT No.1 } & \multicolumn{4}{|c|}{ OWT No.2 } & \multicolumn{4}{|c|}{ OWT No.3 } & \multicolumn{4}{|c|}{ OWT No.4 } & \multicolumn{4}{|c|}{ OWT No.5 } & \multirow[t]{2}{*}{$\begin{array}{c}\text { Cost } \\
\text { Saving/ } \\
\end{array}$} \\
\hline & & \multirow{2}{*}{$\begin{array}{c}\text { Rotor } \\
\text { OM }\end{array}$} & \multicolumn{2}{|c|}{ GeneratorPitch } & \multirow{2}{*}{$\begin{array}{c}\text { Brake } \\
-\end{array}$} & \multirow{2}{*}{$\begin{array}{c}\text { Rotor } \\
\text { OM }\end{array}$} & \multicolumn{2}{|c|}{ GeneratorPitch } & \multirow{2}{*}{$\begin{array}{c}\text { Brake } \\
-\end{array}$} & \multirow{2}{*}{$\begin{array}{c}\text { Rotor } \\
\text { OM }\end{array}$} & \multicolumn{2}{|c|}{ GeneratorPitch } & \multirow{2}{*}{$\begin{array}{c}\text { Brake } \\
-\end{array}$} & \multirow{2}{*}{$\begin{array}{c}\text { Rotor } \\
\text { PM }\end{array}$} & \multicolumn{2}{|c|}{ GeneratorPitch } & \multirow{2}{*}{$\begin{array}{c}\text { Brake } \\
-\end{array}$} & \multirow{2}{*}{$\begin{array}{c}\text { Rotor } \\
-\end{array}$} & \multicolumn{2}{|c|}{ GeneratorPitch } & \multirow{2}{*}{$\begin{array}{c}\text { Brake } \\
-\end{array}$} & \\
\hline \multirow{23}{*}{$\begin{array}{c}\text { Time/ } \\
\text { Day }\end{array}$} & 50 & & - & - & & & - & - & & & - & - & & & - & - & & & - & - & & 76,855 \\
\hline & 100 & $\mathrm{OM}$ & - & - & - & - & $\mathrm{OM}$ & - & - & - & $\mathrm{OM}$ & - & - & $\mathrm{OM}$ & - & PM & - & - & - & $\mathrm{OM}$ & - & 89,262 \\
\hline & 124 & - & - & $\mathrm{OM}$ & - & PM & - & - & - & $\mathrm{OM}$ & - & $\mathrm{OM}$ & - & - & - & - & - & - & - & - & - & 47,808 \\
\hline & 148 & $\mathrm{OM}$ & - & - & - & - & - & - & - & - & - & - & - & $\mathrm{PM}$ & $\mathrm{OM}$ & - & - & $\mathrm{OM}$ & $\mathrm{OM}$ & - & $\mathrm{OM}$ & 109,772 \\
\hline & 188 & - & $\mathrm{OM}$ & - & - & PM & $\mathrm{OM}$ & $\mathrm{OM}$ & - & $\mathrm{OM}$ & - & - & - & $\mathrm{OM}$ & - & $\mathrm{OM}$ & - & - & - & $\mathrm{OM}$ & - & 61,060 \\
\hline & 213 & PM & - & - & - & - & - & - & - & - & $\mathrm{OM}$ & - & - & - & - & - & - & $\mathrm{OM}$ & - & - & - & 17,539 \\
\hline & 240 & - & - & - & - & $\mathrm{OM}$ & - & - & - & - & - & - & - & $\mathrm{OM}$ & $\mathrm{PM}$ & - & - & - & $\mathrm{OM}$ & - & - & 20,546 \\
\hline & 270 & $\mathrm{PM}$ & - & - & - & - & - & - & - & $\mathrm{OM}$ & - & - & - & - & - & - & - & - & - & - & - & 34,887 \\
\hline & 301 & - & $\mathrm{OM}$ & $\mathrm{OM}$ & - & $\mathrm{OM}$ & - & - & - & - & - & $\mathrm{PM}$ & $\mathrm{OM}$ & $\mathrm{OM}$ & $\mathrm{OM}$ & - & $\mathrm{OM}$ & $\mathrm{OM}$ & - & - & - & 96,190 \\
\hline & 327 & $\mathrm{PM}$ & - & - & - & - & $\mathrm{OM}$ & - & - & $\mathrm{OM}$ & - & - & - & - & - & $\mathrm{OM}$ & - & - & $\mathrm{OM}$ & $\mathrm{OM}$ & - & 83,610 \\
\hline & 349 & - & - & - & - & $\mathrm{OM}$ & - & - & - & - & $\mathrm{OM}$ & - & - & $\mathrm{PM}$ & - & - & - & - & - & - & - & 18,810 \\
\hline & 382 & $\mathrm{OM}$ & - & - & - & - & - & - & $\mathrm{OM}$ & - & - & - & - & - & $\mathrm{OM}$ & - & - & $\mathrm{PM}$ & - & - & - & 76,393 \\
\hline & 403 & - & $\mathrm{OM}$ & - & - & - & - & - & - & $\mathrm{OM}$ & - & - & - & PM & - & - & - & - & - & - & $\mathrm{OM}$ & 45,752 \\
\hline & 456 & - & - & $\mathrm{PM}$ & - & - & $\mathrm{OM}$ & - & - & - & - & - & - & $\mathrm{OM}$ & $\mathrm{OM}$ & $\mathrm{OM}$ & - & $\mathrm{OM}$ & - & $\mathrm{OM}$ & - & 122,213 \\
\hline & 486 & $\mathrm{OM}$ & - & - & - & $\mathrm{OM}$ & - & - & - & PM & - & - & - & $\mathrm{OM}$ & - & - & - & - & - & - & - & 59,763 \\
\hline & 522 & - & $\mathrm{OM}$ & - & - & - & - & - & - & - & $\mathrm{PM}$ & - & - & - & - & - & - & $\mathrm{OM}$ & $\mathrm{OM}$ & - & - & 79,922 \\
\hline & 545 & $\mathrm{OM}$ & - & - & - & $\mathrm{OM}$ & $\mathrm{OM}$ & - & - & $\mathrm{OM}$ & - & - & - & $\mathrm{OM}$ & PM & $\mathrm{OM}$ & - & - & - & $\mathrm{OM}$ & - & 95,590 \\
\hline & 597 & $\mathrm{OM}$ & - & $\mathrm{PM}$ & - & $\mathrm{OM}$ & - & - & - & - & - & $\mathrm{OM}$ & - & $\mathrm{OM}$ & - & - & - & $\mathrm{OM}$ & $\mathrm{OM}$ & - & - & 114,192 \\
\hline & 619 & - & $\mathrm{OM}$ & - & - & - & - & PM & $\mathrm{OM}$ & - & - & - & $\mathrm{OM}$ & - & - & - & - & - & - & - & - & 44,445 \\
\hline & 648 & $\mathrm{OM}$ & - & - & - & $\mathrm{OM}$ & - & - & - & - & - & - & - & $\mathrm{PM}$ & - & - & - & $\mathrm{OM}$ & - & - & $\mathrm{OM}$ & 51,566 \\
\hline & 672 & - & - & - & - & - & $\mathrm{OM}$ & $\mathrm{OM}$ & - & - & - & - & - & - & - & PM & - & - & $\mathrm{OM}$ & $\mathrm{OM}$ & - & 59,380 \\
\hline & 689 & - & - & - & - & - & - & - & - & $\mathrm{PM}$ & - & - & $\mathrm{OM}$ & $\mathrm{OM}$ & - & - & $\mathrm{OM}$ & - & - & - & - & 17,264 \\
\hline & 710 & $\mathrm{OM}$ & - & - & $\mathrm{OM}$ & $\mathrm{OM}$ & - & - & - & - & - & - & - & - & $\mathrm{PM}$ & - & - & - & - & - & - & 35,815 \\
\hline
\end{tabular}


Figure 12 shows proportions of total saved maintenance costs of the five main pieces of offshore wind turbine equipment. As the frequency of preventive maintenance is high, the cost saved in rotor maintenance is the minimum and all maintenance activities of braking equipment are completed by the opportunities provided by preventive maintenance of other equipment, so the proportion of the cost saved in braking equipment maintenance is the largest.

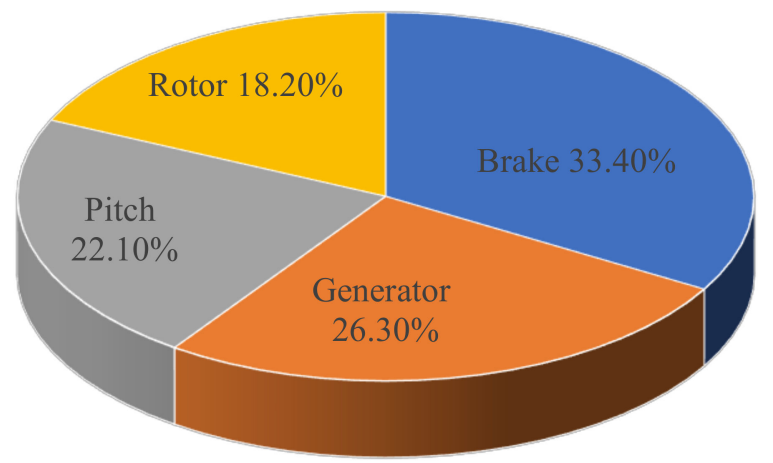

Figure 12. The maintenance cost savings percentage of 5 OWTs main equipments.

Table 7 lists the cost savings of the comprehensive maintenance strategy for 80 offshore wind turbines in the Dafengtian offshore wind farm, and surplus proportions are calculated. Results show that the maintenance investment of offshore wind farm increases with the increase of the number of wind turbines. Using the comprehensive maintenance model in this paper, the cost saving proportion decreases with the increase of the number of wind turbines in the wind farm. However, the cost saving increases with the increase of the number of wind turbines in the wind farm. The daily surplus cost of 80 offshore wind turbines can reach $22,908 ¥$, which proves the advantages and significance of the maintenance model applied to offshore wind farms. In addition, based on a comparison, Dafengtian offshore wind farm now adopts scheduled maintenance method based on fixed cycle, fault maintenance cost accounts for $51 \%$, being about $15,300,000 ¥ /$ year, this maintenance cost accounts for over a half of the total maintenance cost. The preventive opportunistic maintenance strategy proposed in this paper can maintain other high-risk equipment in advance during the maintenance process of one equipment, which can effectively improve equipment availability of the wind power system and reduce maintenance cost of the wind farm and the system. The cost of ship leasing accounts for $21 \%$, about $6,300,000 ¥ /$ year. The maintenance strategy proposed in this paper can establish weather waiting windows and effectively consider the influence of weather accessibility on the maintenance, which is not only closer to the actual offshore maintenance process, but also suitable for leasing and dispatching maintenance vessels, thus reducing the fixed maintenance cost of offshore wind farms.

Table 7. Maintenance cost savings of offshore wind farm with different amount of OWTs. (¥/year).

\begin{tabular}{ccccc}
\hline Number of OWTs & Planned Maintenance Cost & Optimized Maintenance Cost & Saving Cost & Saving Ratio \\
\hline 5 & $1,875,000$ & $1,085,436$ & 2163 & $42.11 \%$ \\
\hline 10 & $3,750,000$ & $2,296,875$ & 3981 & $38.75 \%$ \\
\hline 20 & $7,500,000$ & $4,847,250$ & 7268 & $35.37 \%$ \\
\hline 40 & $15,000,000$ & $10,186,444$ & 13,188 & $32.09 \%$ \\
\hline 80 & $30,000,000$ & $21,638,634$ & 22,908 & $27.87 \%$ \\
\hline
\end{tabular}




\section{Conclusions}

Optimizing offshore wind farm activities is a major challenge. In this paper, based on the rolling horizon approach, a mathematical model was established, comprehensively considering the actual maintenance problems of offshore wind farm, such as accessibility of weather conditions, maintenance quality, running state and economic relevance, etc. The main conclusions are as follows:

(1) An improved factor with Monte Carlo algorithm were presented to simulate the imperfect preventive maintenance activity, the influence of uncertainty of maintenance degree in practical engineering on the system is taken into consideration in the optimization process.

(2) The weather window model of the offshore wind farm is established to calculate the expected waiting window time, so as to consider the impact of weather environment accessibility on offshore wind turbine maintenance. The results show that considering the weather accessibility, it is not only closer to the actual offshore maintenance process, but also suitable for leasing and dispatching maintenance vessels, so as to reduce the fixed maintenance cost of offshore wind farms.

(3) A maintenance grouping optimization method for offshore wind farm considering opportunities and economic relevance is provided. By applying a rolling horizon approach, the maintenance planning which can be changed with time can be updated to take short-term information, into account. The results of Dafengtian offshore wind farm show the practicality and superiority of the proposed method, which can realize the long-term dynamic optimization of offshore wind farm maintenance activities.

(4) There are many uncertainties in offshore wind farm maintenance process, some assumptions have been made in this paper. In the future, more statistical data, such as dynamic equipment failure data, maintenance quality statistics, etc., are needed to establish a more perfect and accurate maintenance model. Meanwhile, artificial intelligence and data mining technology can be applied to realize an intelligent maintenance strategy for smart offshore wind farms.

Author Contributions: Conceptualization, Y.L. and L.S.; methodology, Y.L.; software, Y.X.; validation, Y.L., L.S. and Y.X.; formal analysis, Y.L.; investigation, Y.L.; resources, Y.X.; data curation, Y.L.; writing-original draft preparation, Y.L.; writing—review and editing, Y.L.; visualization, Y.L.; supervision, L.S.; project administration, Y.X.; funding acquisition, Y.L. All authors have read and agreed to the published version of the manuscript.

Funding: This research is funded by the "Research on damage prediction and maintenance strategy of offshore wind turbines based on artificial intelligence method (No. 52001087)" from the National Natural Science Foundation of China.

Institutional Review Board Statement: Not applicable.

Informed Consent Statement: Not applicable.

Data Availability Statement: Not applicable.

Conflicts of Interest: The authors declare no conflict of interest.

\section{References}

1. Shafiee, M. Maintenance logistics organization for offshore wind energy: Current progress and future perspectives. Renew. Energy 2015, 77, 182-193. [CrossRef]

2. James, C.; Alasdair, M. Availability, operation \& maintenance costs of offshore wind turbines with different drive train configurations. Wind Energy 2016, 20, 361-378.

3. Zhang, C.; Gao, W.; Guo, S.; Li, Y.; Yang, T. Opportunistic maintenance for wind turbines considering imperfect, reliability-based maintenance. Renew. Energy 2017, 103, 606-612. [CrossRef]

4. Ding, F.; Tian, Z. Opportunistic maintenance optimization for wind turbine systems considering imperfect maintenance actions. Int. J. Reliab. Qual. Saf. Eng. 2011, 18, 463-481. [CrossRef]

5. Nilsson, J.; Bertling, L. Maintenance management of wind power systems using condition monitoring systems-Life cycle cost analysis for two case studies. IEEE Trans. Energy Convers. 2007, 22, 223-229. [CrossRef] 
6. Carlos, S.; Sánchez, A.; Martorell, S.; Marton, I. Onshore wind farms maintenance optimization using a stochastic model. Math. Comput. Model. 2013, 57, 1884-1890. [CrossRef]

7. Laura, C.S.; Vincente, D.C. Life-cycle cost analysis of floating offshore wind farms. Renew. Energy 2014, 66, 41-48. [CrossRef]

8. Carroll, J.; McDonald, A.; McMillan, D. Failure rate, repair time and unscheduled O\&M cost analysis of offshore wind turbines. Wind. Energy 2016, 19, 1107-1119. [CrossRef]

9. Lu, Y.; Sun, L.; Kang, J.; Sun, H.; Zhang, X. Opportunistic maintenance optimization for offshore wind turbine electrical and electronic system based on rolling horizon approach. J. Renew. Sustain. Energy 2017, 9, 033307. [CrossRef]

10. Ding, F.F.; Tian, Z.G. Opportunistic maintenance for wind farms considering multi-level imperfect maintenance thresh-olds. Renew. Energy 2012, 45, 175-182. [CrossRef]

11. Sun, H.Y.; Zheng, X.Y.; Huang, Y.; Gao, S. Study on offshore personnel transfer technique and crew transfer vessel's sea-keeping performance. J. Ship Mech. 2018, 22, 580-594.

12. Tian, Z.G.; Wong, L. A neural network approach for remaining useful life prediction utilizing both failure and suspen-sion histories. Mech. Syst. Signal Process. 2009, 24, 1542-1555. [CrossRef]

13. Lu, Y.; Sun, L.; Zhang, X.; Feng, F.; Kang, J.; Fu, G. Condition based maintenance optimization for offshore wind turbine considering opportunities based on neural network approach. Appl. Ocean Res. 2018, 74, 69-79. [CrossRef]

14. Wu, Y.-R.; Zhao, H.-S. Optimization maintenance of wind turbines using Markov decision processes. In Proceedings of the 2010 International Conference on Power System Technology, Hangzhou, China, 24-28 October 2010; pp. 1-6.

15. Hagen, B.; Simonsen, I.; Hofmann, M.; Muskulus, M. A multivariate Markov weather model for O\&M simulation of offshore wind parks. Energy Procedia 2013, 35, 137-147. [CrossRef]

16. Zhu, W.J.; Castanier, B.; Bettayeb, B. A dynamic programming-based maintenance model of offshore wind turbine con-sidering logistic delay and weather condition. Reliab. Eng. Syst. Saf. 2019, 190, 106512. [CrossRef]

17. Malik, M.A.K. Reliable preventive maintenance scheduling. AIIE Trans. 1979, 11, 221-228. [CrossRef]

18. Nakagawa, T. Sequential imperfect preventive maintenance policies. IEEE Trans. Reliab. 1988, 37, 295-298. [CrossRef]

19. Kroese, D.P.; Taimre, T.; Botev, Z.I. Handbook of Monte Carlo Methods; Wiley: Hoboken, NJ, USA, 2011.

20. Bian, X.Y.; Yin, J.H.; Fu, Y. Optimized operation and maintenance strategies for offshore wind farm. East China Electr. Power 2012, $40,95-98$.

21. Hosking, J.R.M.; Wallis, J.R. Regional Frequency Analysis: An Approach Based on L-Moments; Cambridge University Press: Cambridge, UK, 2005.

22. Pilar, P.; Soares, C.G.; Carretero, J. 44-year wave hindcast for the North East Atlantic European coast. Coast. Eng. 2008, 55, 861-871. [CrossRef]

23. Walker, R.T.; van Nieuwkoop-McCall, J.; Johanning, L.; Parkinson, R.J. Calculating weather windows: Application to transit, installation and the implications on deployment success. Ocean Eng. 2013, 68, 88-101. [CrossRef] 